\title{
Produtividade da beterraba e rúcula em função da época de plantio em monocultivo e consórcio
}

\author{
Leilson C Grangeiro ${ }^{1}$; Francisco Bezerra Neto ${ }^{1}$; Maria Zuleide de Negreiros ${ }^{1}$; Arthur Bernardes Cecílio \\ Filho $^{2}$; Andrezza Valéria C e Caldas ${ }^{1}$; Núbia L da Costa ${ }^{1}$ \\ ${ }^{1}$ UFERSA, Depto. Ciências Vegetais, C. postal 137, 59625-900 Mossoró-RN; ${ }^{2}$ UNESP-FCAV, Depto. Produção Vegetal, Via de Acesso \\ Prof. Paulo Donato Castellane, s/n, 14884-900 Jaboticabal-SP; leilson@ufersa.edu.br
}

\section{RESUMO}

Avaliou-se os rendimentos das culturas da beterraba e da rúcula em função de épocas de plantio e sistemas solteiro e consorciado, em Mossoró, de janeiro a março de 2005. O delineamento experimental utilizado foi de blocos casualizados com nove tratamentos em quatro repetições. Os tratamentos consistiram dos consórcios da beterraba com rúcula estabelecidos aos $0,7,14$ e 21 dias após a semeadura da beterraba, monocultura da beterraba e as monoculturas da rúcula, nas mesmas épocas de estabelecimento dos cultivos consorciados. A semeadura da rúcula e beterraba realizada na mesma época proporcionaram maior massa fresca e seca da parte aérea e produtividade de rúcula, sendo respectivamente, de 50,19 g/planta; $5,86 \mathrm{~g} /$ planta e $1338,47 \mathrm{~g} / \mathrm{m}^{2}$. Já para a beterraba, independentemente da época de semeadura, o monocultivo foi superior ao consórcio na produção de massa fresca e de raízes. Os maiores índices de uso eficiente da terra foram obtidos no sistema de consórcio quando a semeadura da rúcula foi realizada no mesmo período $(2,0)$ e aos sete dias $(1,9)$ após a semeadura da beterraba.

Palavras-chave: Beta vulgaris, Eruca sativa, eficiência agronômica, rendimento.

\section{ABSTRACT}

Yield of sugar beet and rocket depending on planting times in sole crop and intercropping system

The yield of sugar beet and rocket was evaluated, as a result of planting times in sole crop and intercropping system. The experiment was carried out in Mossoró, from January to March,f 2005. The experimental design was of randomized complete blocks with nine treatments and four replications. The treatments consisted of the intercrops of sugar beet with rocket established at $0,7,14$ and 21 days after sugar beet sowing date, as well as of sugar beet and rocket cultivated as sole crops, planted at the same times of the intercropping establishment. The highest values of fresh shoot ( $50.19 \mathrm{~g} / \mathrm{plant})$, dry mass $(5.86 \mathrm{~g} / \mathrm{plant})$ and yield $\left(1338.47 \mathrm{~g} / \mathrm{m}^{2}\right)$ of rocket were observed in the intercropping systems established at the same time. The highest values of shoot fresh mass and root yield of sugar beet were observed in sole crop. The highest land equivalent ratios were obtained in the intercropping systems where the rocket was sown at the same time of sugar beet and 7 days after sugar beet crop.

Keywords: Beta vulgaris, Eruca sativa, agronomic efficiency, yield.

(Recebido para publicação em 11 de julho de 2006; aceito em 8 de outubro de 2007)

$\mathrm{N}_{\mathrm{a}}^{\circ}$ estado do Rio Grande do Norte, a produção de algumas hortaliças é restrita e pouco expressiva como no caso da rúcula, sendo cultivada por pequenos produtores e próximo aos centros consumidores. No caso da beterraba, embora seja uma hortaliça de maior expressão, o estado não produz o suficiente para atender a sua demanda, sendo importada de outras regiões. É prática comum, entre os produtores de hortaliças do estado, a utilização do consórcio, envolvendo as culturas do coentro, alface, tomate, pimentão, abóbora e moranga.

A consorciação de culturas é uma alternativa promissora para os produtores que atuam com recursos estruturais e financeiros limitados (Oliveira et al., 2004), e consiste na combinação do cultivo de duas ou mais espécies, com diferentes ciclos e arquiteturas vegetativas, exploradas simultaneamente, na mesma área, procurando maximizar os lucros e aproveitar melhor os insumos e a mãode-obra (Caetano et al.,1999).

As culturas envolvidas nesse sistema não são necessariamente, semeadas ao mesmo tempo, mas durante parte do seu desenvolvimento haverá uma simultaneidade, forçando a interação entre elas. Para tanto, é importante a escolha de culturas companheiras que exerçam alguma complementaridade. Isso é possível quando as espécies consorciadas apresentam nichos ecológicos diferentes resultando em melhor utilização da luz e absorção de nutriente que uma única cultura numa área e tempo determinados. Segundo Khatounian (2001), a diversificação de culturas é o ponto chave para a manutenção da fertilidade dos sistemas, para o controle de pragas e doenças e para a estabilidade econômica regional.

Na região de Mossoró são escassas as pesquisas realizadas sobre o consór- cio de hortaliças, sendo amplas as possibilidades de estudo. Entretanto, já ficou comprovada a eficiência agroeconômica de sistemas de cultivo consorciados entre as culturas da cenoura e alface (Bezerra Neto et al., 2001; Negreiros et al., 2002; Bezerra Neto et al., 2003; Oliveira et al., 2004; Bezerra Neto et al., 2005), alface e coentro (Freitas et al., 2004; Oliveira et al., 2005) e beterraba e alface (Azevedo Júnior, 1990).

Neste trabalho foi avaliado o rendimento da beterraba e da rúcula em função de diferentes épocas de plantio, em monocultivo e em consórcio, nas condições de Mossoró-RN.

\section{MATERIAL E MÉTODOS}

O experimento foi realizado na Universidade Federal Rural do Semi-Árido em Mossoró, de janeiro a março de 
Tabela 1. Massa fresca, seca e produtividade de rúcula em função dos sistemas de cultivo e época de estabelecimento do consórcio (Fresh and dry mass and yield of rocket as a function of cropping systems and intercropping establishment times). Mossoró, UFERSA, 2005.

\begin{tabular}{|c|c|c|c|c|}
\hline \multirow{3}{*}{ Sistemas de cultivo } & \multicolumn{4}{|c|}{ Época de semeadura da rúcula (dias) } \\
\hline & \multicolumn{4}{|c|}{ Massa fresca (g/planta) } \\
\hline & 0 & 7 & 14 & 21 \\
\hline Monocultivo & $35,53 \mathrm{~b}$ & $41,11 \mathrm{a}$ & $43,20 \mathrm{a}$ & $33,86 a$ \\
\hline Consórcio & $50,19 a$ & $47,27 \mathrm{a}$ & $30,53 \mathrm{a}$ & $18,37 \mathrm{~b}$ \\
\hline \multirow[t]{2}{*}{$\mathrm{CV}(\%)$} & 24,0 & & & \\
\hline & \multicolumn{4}{|c|}{ Massa seca (g/planta) } \\
\hline Monocultivo & $4,14 \mathrm{~b}$ & $5,70 \mathrm{a}$ & $5,53 \mathrm{a}$ & $5,19 a$ \\
\hline Consórcio & $5,86 a$ & 5,68 a & 4,37 a & $3,24 \mathrm{~b}$ \\
\hline \multirow[t]{2}{*}{$\mathrm{CV}(\%)$} & 16,5 & & & \\
\hline & \multicolumn{4}{|c|}{ Produtividade $\left(\mathrm{g} / \mathrm{m}^{2}\right)$} \\
\hline Monocultivo & $947,42 \mathrm{~b}$ & $1096,20 \mathrm{a}$ & 1152,13 a & 903,07 a \\
\hline Consórcio & $1338,47 a$ & $1260,53 a$ & $814,20 \mathrm{a}$ & $489,93 \mathrm{~b}$ \\
\hline $\mathrm{CV}(\%)$ & 24,1 & & & \\
\hline
\end{tabular}

Médias seguidas de mesma letra minúscula na coluna para cada característica, não diferem ente si ao nível de 5\% pelo teste de Tukey, (means followed by the same small letters in the column did not differ from each other; Turkey 5\%).

2005, em solo classificado como Argissolo Vermelho-amarelo (Alfissol) (EMBRAPA, 1999). Da área experimental foram retiradas amostras de solo, cuja análise química resultou: $\mathrm{pH}$ (água) $=7,9 ; \mathrm{P}=166 \mathrm{mg} \mathrm{dm}^{-3} ; \mathrm{K}=0,24 \mathrm{cmol}_{\mathrm{c}}$ $\mathrm{dm}^{-3} ; \mathrm{Ca}=5,2 \mathrm{cmol}_{\mathrm{c}} \mathrm{dm}^{-3}, \mathrm{Na}=0,47$ $\mathrm{cmol}_{\mathrm{c}} \mathrm{dm}^{-3}$ e $\mathrm{Mg}=3,5 \mathrm{cmol}_{\mathrm{c}} \mathrm{dm}^{-3}$.

Para interpretação dos dados relativos à beterraba, efetuou-se a análise de variância sob delineamento de blocos casualizados, com cinco tratamentos, os quais corresponderam à beterraba em monocultura e quatro consórcios com a rúcula $(0,7,14$ e 21 dias após a semeadura da beterraba (DAS)). Para as características da rúcula, a análise de variância seguiu o modelo de blocos casualizados, em esquema fatorial 2 (sistema de cultivo, consórcio e monocultivo) x 4 (época de semeadura da rúcula: 0, 7, 14 e 21 DAS). Para a época de semeadura da rúcula foi feita análise de regressão, enquanto que para os sistemas de cultivos foi empregado o teste de Tukey, ao nível de 5\% de probabilidade para comparação das médias.

A unidade experimental teve área total de $1,5 \mathrm{~m}^{2}$, compreendendo cinco linhas de plantio de beterraba em consórcio, ou em monocultura. Para a rúcula, foram considerados cinco linhas em monocultura e quatro linhas em consórcio. $\mathrm{O}$ espaçamento empregado para as duas culturas foi de $0,30 \mathrm{~m}$ entrelinhas e $0,10 \mathrm{~m}$ entre plantas. A área útil da parcela foi de $0,54 \mathrm{~m}^{2}$, nos dois sistemas de plantio. Nos consórcios, a semeadura da rúcula foi realizada no sentido longitudinal do canteiro, nas entrelinhas da beterraba.

O preparo do solo constou de uma gradagem, seguida do levantamento dos canteiros. As adubações de plantio e de cobertura para as duas culturas, foram realizadas com base na análise de solo e recomendação de Cavalcanti (1998). Para a monocultura da rúcula foi realizada uma adubação de cobertura aos 15 dias após a semeadura e para beterraba (monocultura e consorciada) duas coberturas, aos 20 e 40 dias após a semeadura.

As quantidades de NPK aplicadas em fundação foram de $40 \mathrm{~kg} \mathrm{ha}^{-1}$ de $\mathrm{N}$, $60 \mathrm{~kg} \mathrm{ha}^{-1}$ de $\mathrm{P}_{2} \mathrm{O}_{5}$ e $30 \mathrm{~kg} \mathrm{ha}^{-1}$ de $\mathrm{K}_{2} \mathrm{O}$ na monocultura da beterraba, $30 \mathrm{~kg} \mathrm{ha}^{-1}$ de $\mathrm{N}, 60 \mathrm{~kg} \mathrm{ha}^{-1}$ de $\mathrm{P}_{2} \mathrm{O}_{5}$ e $30 \mathrm{~kg} \mathrm{ha}^{-1}$ de $\mathrm{K}_{2} \mathrm{O}$ na monocultura da rúcula e $60 \mathrm{~kg}$ $\mathrm{ha}^{-1}$ de N, $90 \mathrm{~kg} \mathrm{ha}^{-1}$ de $\mathrm{P}_{2} \mathrm{O}_{5}$ e $45 \mathrm{~kg} \mathrm{ha}^{-1}$ de $\mathrm{K}_{2} \mathrm{O}$ nos consórcios, utilizando respectivamente como fonte de nitrogênio, fósforo e potássio a uréia, superfosfato triplo e cloreto de potássio. Em cobertura, $40 \mathrm{~kg} \mathrm{ha}^{-1}$ de $\mathrm{N}$ nas monoculturas e $60 \mathrm{~kg} \mathrm{ha}^{-1}$ de $\mathrm{N}$ mais $45 \mathrm{~kg} \mathrm{ha}^{-1}$ de $\mathrm{K}_{2} \mathrm{O}$ nos consórcios, também na forma de uréia e cloreto de potássio.

A beterraba, cultivar Early Wonder, foi semeada em covas, utilizando quatro sementes. Após 14 dias foi realizado o desbaste, deixando apenas uma planta por cova, tanto para a monocultura como para o cultivo consorciado. A rúcula, cultivar Cultivada, no sistema de monocultura foi semeada da mesma forma como procedido para a beterraba, contudo, desbastando aos sete dias após, deixando-se uma planta por cova. No consórcio, a semeadura da rúcula foi realizada conforme as épocas pré-estabelecidas.

O controle de plantas invasoras foi realizado com capinas manuais e as irrigações por microaspersão com lâmina média diária de $6,0 \mathrm{~mm}$. A colheita da beterraba foi realizada aos 60 dias e da rúcula aos 30 dias após a semeadura.

Avaliou-se a massa fresca e seca da parte aérea da rúcula, massa fresca e seca de raiz da beterraba, produtividade da beterraba e da rúcula e o índice de uso eficiente da terra (UET), utilizada para avaliar a eficiência do consórcio em relação às monoculturas, obtida pela expressão: $\mathrm{UET}=\left(\mathrm{C}_{\mathrm{a}} / \mathrm{M}_{\mathrm{a}}\right)+\left(\mathrm{C}_{\mathrm{r}} / \mathrm{M}_{\mathrm{r}}\right)$ onde, $\mathrm{Ca}$ e $\mathrm{Cr}$ são, respectivamente, as produtividades em consorciação e Ma e $\mathrm{Mr}$ as produtividades em monocultura da beterraba e rúcula, respectivamente (Willey, 1979).

\section{RESULTADOS E DISCUSSÃO}

Houve interação significativa, entre os sistemas de cultivo e época de semeadura da rúcula, para massa fresca e seca da parte aérea e produtividade (Tabela 1).

Desdobrando-se a interação, sistemas de cultivos dentro de época de semeadura, observou-se superioridade do consórcio em relação à monocultura na massa fresca e seca da parte aérea e na produtividade da rúcula, somente quando a semeadura da rúcula foi realizada na mesma época da beterraba. Quando o consórcio foi estabelecido aos 7 e 14 dias, não houve diferença significativa entre os sistemas. Já o estabelecimento do consórcio mais tardio, ou seja, 21 dias após a semeadura da beterraba, a monocultura foi superior ao consórcio. Nesse período a redução foi de 42,3; 37,6 e $45,7 \%$, respectivamente, para massa fresca, massa seca e produtividade (Tabela 1). Esse baixo desempenho da rúcula, quando semeada mais tardiamente em relação à beterraba, possivelmente foi devido à competição 
interespecífica, pois a maior altura das plantas de beterraba proporcionou o sombreamento da rúcula.

Esses resultados diferem dos obtidos por Cecílio Filho et al. (2003), que verificaram, independentemente da época de semeadura, maior produtividade e massa seca da rúcula, demonstrando efeito negativo do sistema consorciado. Possivelmente, os resultados divergentes devam-se à diferença das condições de cultivo, já que o experimento dos referidos autores foi conduzido em Jaboticabal onde o tipo de solo e as condições climáticas são diferentes daquelas do presente trabalho. Variações no ambiente de cultivo podem determinar respostas diferenciadas das espécies em consórcio, conforme salientou Cecílio Filho (2005) e consequentemente, verificar-se relações distintas entre as espécies, ou seja, competição independente e cooperação.

No entanto, quando Cecílio Filho et al. (2003) compararam as épocas de semeadura dentro do sistema consorciado, verificaram, como no presente trabalho, uma redução na produtividade da rúcula no consórcio estabelecido aos 21 dias após o transplantio da beterraba. Segundo Hortwith (1985) é comum constatar-se maior redução no desenvolvimento e na produção de culturas consorciadas, sobretudo nas instaladas com atraso.

O desdobramento da interação épocas de semeadura dentro de sistemas de cultivo, para a massa fresca e seca da parte aérea de rúcula foi significativo apenas para o sistema de cultivo em consórcio (Figuras 1 e 2). Quando as semeaduras da rúcula e beterraba foram realizadas na mesma época, houve maior produção de massa fresca e seca da parte aérea da rúcula. A partir de então, ocorreu um decréscimo acentuado, sendo, respectivamente, de 65,2 e $46,2 \%$, para massa fresca e seca, quando comparado com o consórcio estabelecido aos 21 dias após a semeadura da beterraba (Figura 1).

Provavelmente as reduções nas massas fresca e seca da parte aérea da rúcula, quando em consórcio com a beterraba mais tardiamente, foram devidas ao efeito da competição da beterraba pois, embora a rúcula apresente um cresci-

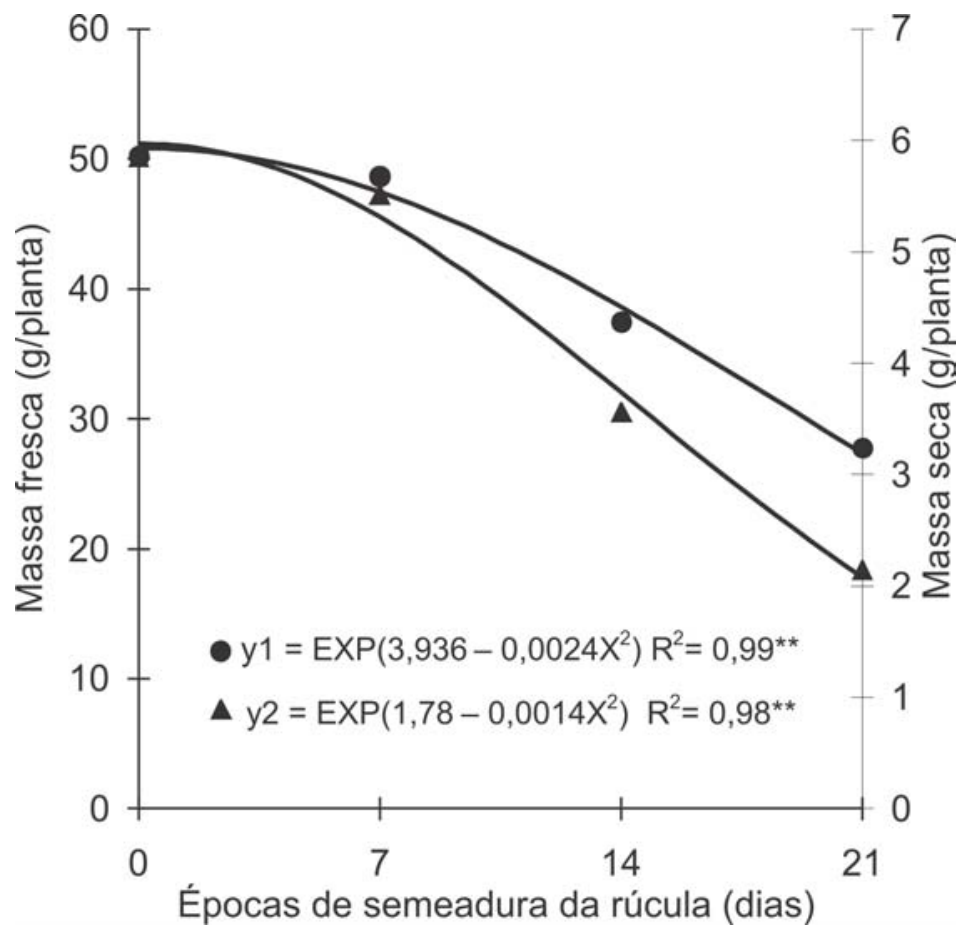

Figura 1. Massa fresca (y1) e seca (y2) da parte aérea de rúcula em cultivo consorciado com beterraba, em função das épocas de semeadura (Fresh (y1) and dry mass (Y2) of shoot in intercropping with sugar beet as a function of planting times rocket). Mossoró, UFERSA, 2005.

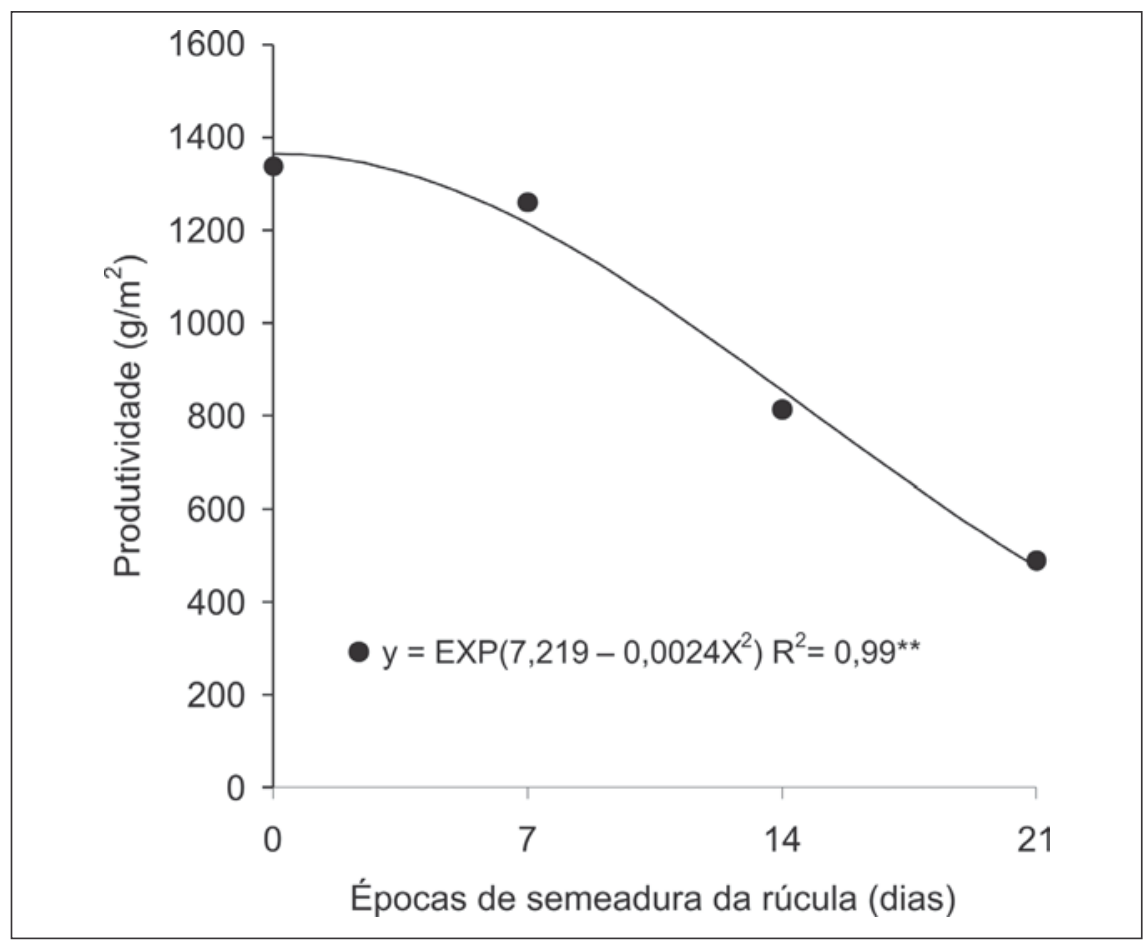

Figura 2. Produtividade de rúcula em cultivo consorciado com beterraba, em função das épocas de semeadura (Yield of rocket in intercropping with sugar beet as a function of planting times). Mossoró, UFERSA, 2005.

mento inicial mais rápido, o sombreamento ocasionado pela beterraprincipalmente a competição por luz, ba nas épocas subseqüentes favoreceu limitando desta forma, o desenvolvimento das plantas de rúcula. 


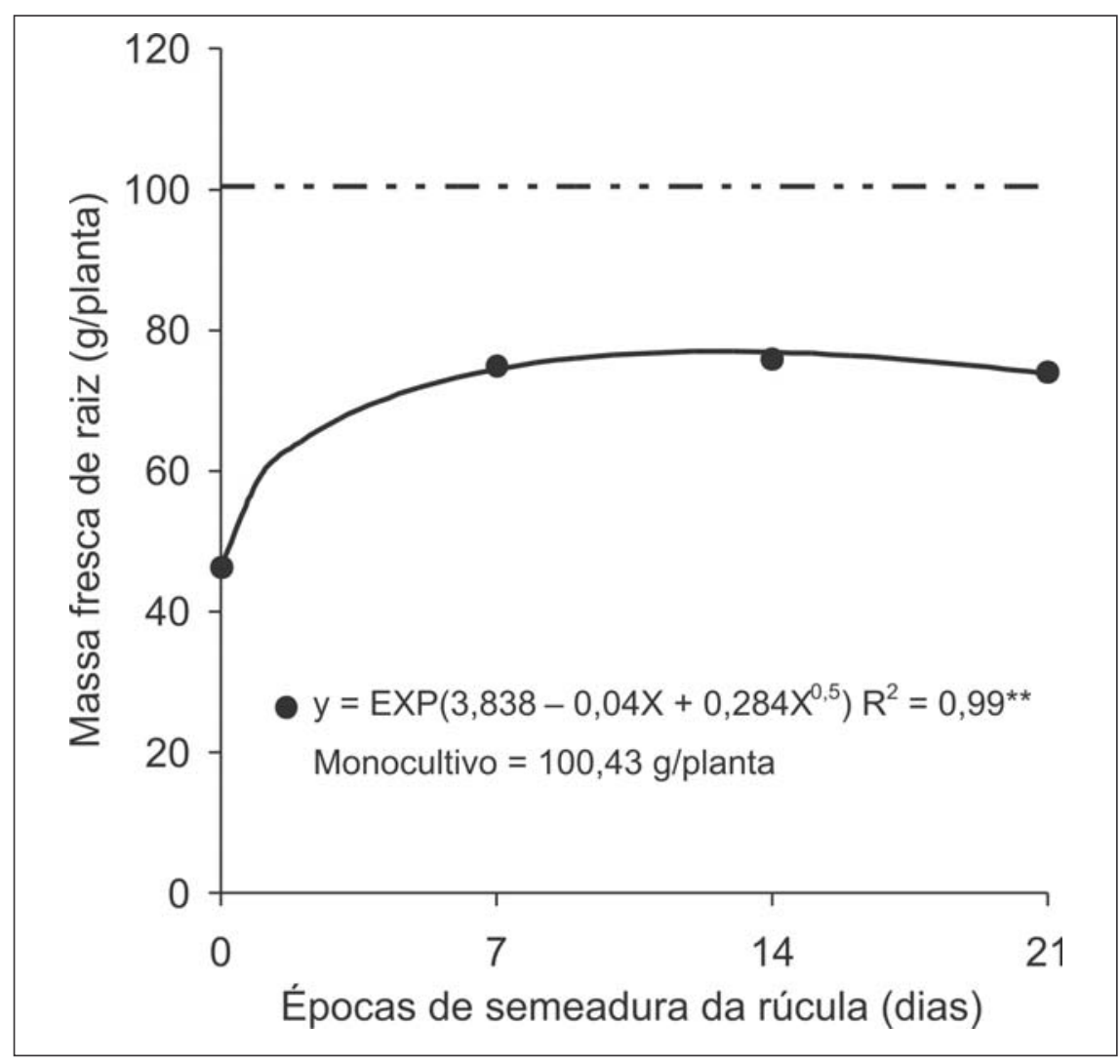

Figura 3. Massa fresca de raiz de beterraba em função das épocas de semeadura da rúcula (Fresh root mass of sugar beet as a function of planting times). Mossoró, UFERSA, 2005.

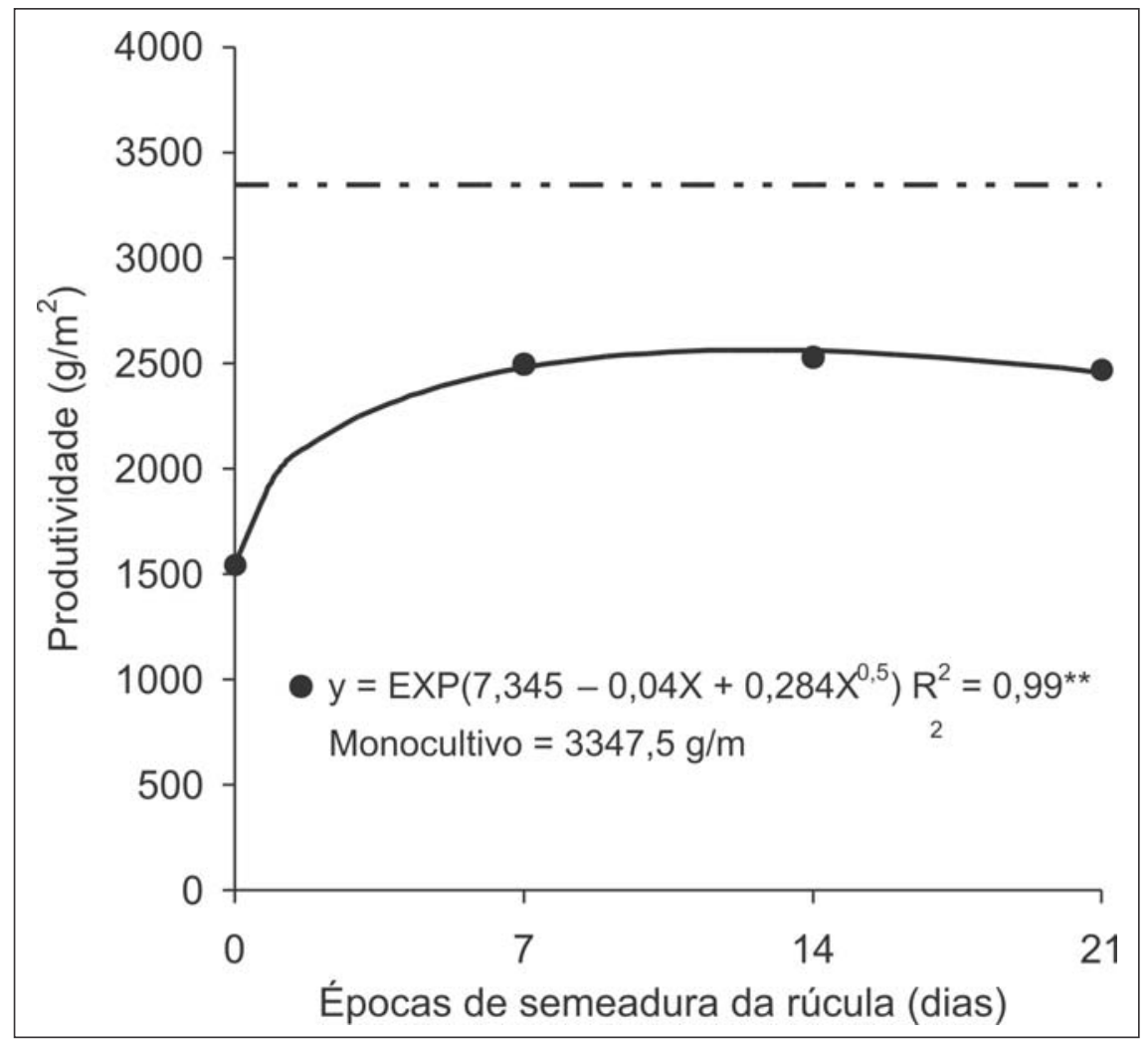

Figura 4. Produtividade de raiz de beterraba em função das épocas de semeadura da rúcula (Yield root of sugar beet as a function of planting times). Mossoró, UFERSA, 2005.
Para a característica produtividade da rúcula, o comportamento foi semelhante ao observado para massa fresca e seca. Quando a semeadura da rúcula foi realizada na mesma época da beterraba, obteve-se maior produtividade (Figura 2), sendo superior em aproximadamente $187 \%$ àquela obtida quando o consórcio foi estabelecido aos 21 dias, confirmando o efeito competitivo entre as espécies, nas semeaduras mais tardias. Comportamentos semelhantes foram observados por Nardin et al. (2002a) e Nardin et al. (2002b) quando trabalharam com essas mesmas espécies consorciadas, sendo que no primeiro a implantação da cultura da beterraba foi por mudas e no segundo por meio de semeadura direta.

A massa fresca e a produtividade de raízes de beterraba, independentemente da época de semeadura da rúcula, foram menores no sistema consorciado em relação à monocultura, demonstrando, que a beterraba foi negativamente influenciada, quando consorciada com a rúcula.

Dentro do consórcio, a semeadura da beterraba e da rúcula na mesma época, promoveu maior redução da massa fresca e produtividade de raízes de beterraba. Essa redução foi respectivamente, de 53,7 e $40 \%$ em relação à monocultura e a época estimada de 13 dias, responsável pela maior massa fresca $(76,9 \mathrm{~g}$ plan$\mathrm{ta}^{-1}$ ) e produtividade de raízes (2563 $\mathrm{g}$ $\mathrm{m}^{-2}$ ) no consórcio (Figuras 3 e 4). Esses resultados são discordantes daqueles encontrados por Nardin et al. (2002b) que não obtiveram diferença na produtividade de raízes de beterraba, entre os sistemas de cultivo nas diferentes épocas de estabelecimento do consórcio. Provavelmente as condições edafoclimáticas do local de realização do trabalho (Jaboticabal), favoreceram o maior ciclo da beterraba (85 dias), superior aos 60 dias ocorridos neste trabalho. Essa divergência pode retratar a diferença térmica entre as localidades, favorecendo a maior precocidade em Mossoró e, também no caso de Jaboticabal, permitiu que houvesse maior tempo após a colheita da rúcula para que a beterraba formasse a raiz tuberosa.

O ciclo da cultura e a semelhança na arquitetura da planta parecem ter sido 
determinantes, para que ocorresse menor produtividade da beterraba no sistema consorciado pois, embora a rúcula apresente ciclo curto, mas com crescimento inicial rápido, promoveu maior competição interespecífica principalmente por luz, quando as semeaduras da beterraba e rúcula foram realizadas simultaneamente. Já no consórcio estabelecido mais tardiamente, ou seja, a partir dos sete dias, a maior competição entre as espécies parece ter sido por água e nutrientes, considerando que, a cultura da beterraba tem maior demanda por esses fatores após os 40 dias (Souza et al., 2006); ainda, a semeadura mais tardia promoveu uma convivência maior das espécies nestes períodos.

A cultura da beterraba também apresentou desempenho inferior quando consorciada com mandioquinha-salsa, sendo a produtividade de raízes de beterraba em cultivo solteiro $69,26 \%$ superior ao consórcio, enquanto que para a massa seca, essa diferença foi de $55,36 \%$ (Tolentino Júnior et al., 2002). Segundo os autores, as relações fontedreno podem ser alteradas pelas condições de cultivo e pelas diferenças de solo, clima e estádio fisiológico das culturas. Outra provável causa da menor produtividade da beterraba consorciada é a maior competição com a mandioquinha-salsa por água, nutrientes, oxigênio e luz, uma vez que a beterraba foi colhida aos 115 dias após o transplante e, nessa época, as plantas da mandioquinha-salsa encontravam-se no estádio de maior crescimento vegetativo.

Sudo et al. (1997), estudando a beterraba 'Tall Top Early Wonder' em consorciação com a alface 'Regina 71', em cultivo orgânico, obtiveram 32,20 t $\mathrm{ha}^{-1}$ e $28,90 \mathrm{t} \mathrm{ha}^{-1}$ de raízes para a beterraba em monocultura e consorciada, respectivamente. Müeller (1996), estudando o consórcio beterraba com alho, obtiveram produtividades de beterraba de 33,08 t ha $^{-1}$ em cultivo solteiro e de 18,45 $\mathrm{t} \mathrm{ha}^{-1}$ no consorciado.

Com relação ao uso eficiente da terra, verifica-se melhor aproveitamento dos recursos ambientais disponíveis nos sistemas consorciados, em relação ao sistema solteiro. Os maiores valores foram observados quando a semeadura da rúcula foi realizada no mesmo período da beterraba $(2,0)$ e aos sete dias $(1,9)$, seguidos dos consórcios aos $14(1,5)$ e
21 dias (1,3). Esses índices correspondem à produção respectivamente, de 100 e $90 \%$ a mais de beterraba e rúcula em um hectare de consórcio em relação à mesma área de cultivos solteiros. Resultados semelhantes foram obtidos por Cecílio Filho et al. (2003), em consórcio de beterraba com rúcula. Segundo Gonçalves (1982), índices de uso eficiente da terra maiores que a unidade, indicam efeito de cooperação ou de compensação entre as culturas consorciadas, com vantagens para o consórcio.

Pode-se concluir que o cultivo consorciado da beterraba com a rúcula foi adequado do ponto de vista agronômico, sendo mais viável com o estabelecimento do consórcio até sete dias após a semeadura da beterraba. Pode ser considerado um sistema de cultivo vantajoso ao produtor, pois com a cultura intercalar da rúcula, obteve-se uma produção adicional e otimizou as práticas culturais tais como capina, irrigação e adubação.

\section{REFERÊNCIAS}

AZEVEDO JÚNIOR MS. 1990. Influência da configuração de plantio e cultivo no consórcio de beterraba (Beta vulgaris L.) e alface (Lactuca sativa L..). Mossoró: ESAM. 43p (Tese mestrado).

BEZERRA NETO F; ANDRADE FV; SANTOS JÚNIOR JJ; NEGREIROS MZ. 2001. Desempenho da cenoura em cultivo solteiro e consorciado com quatro cultivares de alface em dois sistemas de cultivos em faixa. In: $\mathrm{CON}$ GRESSO BRASILEIRO DE OLERICULTURA, 41. Resumos... Brasília: SOB (CD-ROM).

BEZERRA NETO F; ANDRADE FV; NEGREIROS MZ; SANTOS JÚNIOR JS. 2003. Desempenho agroeconômico do consórcio cenoura $\mathrm{x}$ alface lisa em dois sistemas de cultivo. Horticultura Brasileira 21: 635-641.

BEZERRA NETO F; BARROS JÚNIOR AP; NEGREIROS MZ; OLIVEIRA EQ; SILVEIRA LM; CÂMARA MJT. 2005. Associação de densidades populacionais de cenoura e alface no desempenho agronômico da cenoura em cultivo consorciado em faixa. Horticultura Brasileira 23: 233-237.

CAETANO LCS; FERREIRA JM; ARAÚJO ML. 1999. Produtividade de cenoura e alface em sistemas de consórcio. Horticultura Brasileira 17: 143-146.

CAVALCANTI FJA. 1998. Recomendações de adubação para o estado de Pernambuco: $2^{\mathrm{a}}$ aproximação. Recife: IPA. 198 p.

CECÍLIO FILHO AB; TAVEIRA MCG; GRANGEIRO LC. 2003. Productivity of beet and roquette cultivation as a function of time of establishing intercropping. Acta Horticuturae 607: 91-95.
CECÍlLIO FILHO AB. 2005. Cultivo consorciado de hortaliças: desenvolvimento de uma linha de pesquisa. Jaboticabal: UNESP-FCAV. 85p (Tese livre docência).

EMBRAPA - Empresa Brasileira de pesquisa Agropecuária. Centro Nacional de Pesquisa de Solo. 1999. Sistema Brasileiro de Classificação de Solos, Brasília: EMBRAPA. Produção de Informação, Rio de Janeiro: EMBRAPA Solos. 141p.

FREITAS KKC; NEGREIROS MZ; BEZERRA NETO F; AZEVEDO CMSB; OLIVEIRA EQ; BARROS JÚNIOR AP. 2004. Uso de efluente e água de rio no desempenho agroeconômico de cenoura, alface e coentro em associação. Caatinga 17: 98-104.

HORWITH B. 1985. A role for intercropping in modern agriculture. Biosciense 35: 286-291.

GONÇALVES SR. 1982. Consorciação de culturas: técnicas de análises e estudo da distribuição do LER. Brasília: UNB - FAMV. 217p. (Tese mestrado).

KHATOUNIAN CA. 2001. A reconstrução ecológica da agricultura. Botucatu: Agroecológica. 348 p.

MÜELLER S. 1996. Produtividade e rentabilidade dos consórcios alho-cenoura e alho-beterraba submetidos a distintos sistemas de controle das plantas daninhas. Jaboticabal: UNESP - FCAV. 201p. (Tese doutorado).

NARDIN RR; CATELAN F; CELILIO FILHO AB. 2002a. Efeito da consorciação sobre as produtividades da rúcula e da beterraba estabelecida por transplantio de mudas. In: CONGRESSO BRASILEIRO DE OLERICULTURA, $42 . \quad$ Resumos... Uberlândia: SOB (CD-ROM).

NARDIN RR; CATELAN F; CECILIO FILHO AB. 2002b. Efeito do cultivo intercalado de rúcula e beterraba estabelecida por semeadura direta, sobre as produtividades das culturas. In: CONGRESSO BRASILEIRO DE OLERICULTURA, 42. Resumos... Uberlândia: SOB (CD-ROM).

NEGREIROS MZ; BEZERRA NETO F; PORTO VCN; SANTOS RHS. 2002. Cultivares de alface em sistemas solteiro e consorciado com cenoura em Mossoró. Horticultura Brasileira 20: 162-166.

OLIVEIRA EQ; BEZERRA NETO F; NEGREIROS MZ; BARROS JÚNIOR AP. 2004. Desempenho agroeconômico do bicultivo de alface em sistema solteiro e consorciado com cenoura. Horticultura Brasileira 22: 712-717.

OLIVEIRA EQ; BEZERRA NETO F; NEGREIROS MZ; BARROS JÚNIOR AP; FREITAS KKC; SILVEIRA LM; LIMA, JSS. 2005. Produção e valor agroeconômico no consórcio entre cultivares de coentro e de alface. Horticultura Brasileira 23: 285-289.

SUDO A; GUERRA JGM; ALMEIDA DL; RIBEIRO RLD. 1997. Desempenho de alface (Lactuca sativa L.) e beterraba (Beta vulgaris L. ) consorciadas em sistema orgânico de produção. In: In: CONGRESSO BRASILEIRO DE OLERICULTURA, 37. Resumos... Manaus: SOB (Resumo 308).

TOLENTINO JUNIOR CF; ZÁRATE NAH; VIEIRA MC. 2002. Produção da mandioquinha-salsa consorciada com alface e beterraba. Acta Scientiarum 24: 1447-1454.

WILLEY RW. 1979. Intercropping - Its importance and research needs. Part. 1 Competition and advantages. Field Crop Abstract 32: 1-10. 